\author{
Suraj Wasudeo Nagre* \\ Department of CVTS, Grant Medical College, \\ Mumbai, India
}

Dates: Received: 02 June, 2016; Accepted: 22 July, 2016; Published: 23 July, 2016

*Corresponding author: Dr. Suraj Wasudeo Nagre, Assistant Professor, Department of CVTS, Grant Medical College, 31, Trimurti Building,J J Hospital compound, Byculla , Mumbai, Pin -400008, Tel: 09967795303; E-mail: surajnagre@yahoo.com

www.peertechz.com

ISSN: 2455-2976

Keywords: Congenital heart disease; Arterial switch; Atrial switch; Transposition of great arteries

\section{Research Article \\ Historical Evolution of Surgery for Transposition of Great Arteries (TGA)}

\section{Introduction}

The science and art of cardiac surgery has made rapid development in the past 65 years. The surgery for transposition of great arteries (TGA) symbolises the manner in which cardiac surgery has progressed. The eventually successful solution in the form of the now popular arterial switch operation (ASO) was elucidated after multiple contributions from several surgical stalwarts and geniuses over more than 35 years (Figure 1). This review traces the various milestones along this journey.

The first morphological description of TGA can be credited to Baillie in 1797 [1], while the term 'Transposition of Great Arteries' was used for the first time by Farre in 1814 [2]. Though the term 'transposition' was used aberrantly in literature till 1970, the ambiguity was resolved by Van Praagh et al., in 1971 who said that, it refers to the aorta and pulmonary artery $(\mathrm{PA})$ being displaced across the ventricular septum [3].

Complete transposition of the great arteries is also known as d-TGA; the "d-" refers to the dextroposition of the bulboventricular

\begin{tabular}{|c|c|c|}
\hline Year & Author & Contribution \\
\hline 1797 & Baillie & First morphological description of TGA \\
\hline 1814 & Farre & First used the term TGA \\
\hline 1948 & Hanlon and Blalock & $\begin{array}{l}\text { Atrial septectomy - first palliative } \\
\text { operation }\end{array}$ \\
\hline 1953 & Lillehei and Varco & Partial venous switch \\
\hline 1955 & Thomas Baffes & Baffes operation \\
\hline 1957 & Ake Senning & Atrial switch using atrial flaps \\
\hline 1963 & William Mustard & Atrial switch using pericardium \\
\hline 1966 & Rashkind and Miller & Introduced balloon atrial septostomy \\
\hline 1975 & Jatene et al. & Successful arterial switch \\
\hline 1981 & Lecompte et al. & Lecompte maneuver \\
\hline 1976 & Magdi Yacoub & $\begin{array}{l}\text { Left ventricular training and two-stage } \\
\text { arterial switch }\end{array}$ \\
\hline 1984 & $\begin{array}{l}\text { Castaneda and } \\
\text { colleagues }\end{array}$ & Neonatal arterial switch \\
\hline 1989 & $\begin{array}{l}\text { Jonas and } \\
\text { colleagues }\end{array}$ & Rapid two-stage arterial switch \\
\hline
\end{tabular}

Figure 1: Significant milestones in the evolution of surgery for transposition of great arteries (TGA). loop (ie, the position of the RV, which is on the right side). The aorta also tends to be on the right and anterior, and the great arteries are parallel rather than crossing as they do in the normal heart. Because the systemic and pulmonary circulations run in parallel, there has to be a communication between the 2, either with an atrial septal defect, a ventricular septal defect (VSD), or at the great arterial level (patent ductus arteriosus) to support life. These connections allow systemic blood to enter the pulmonary circulation for oxygenation and allow oxygenated blood from the pulmonary circuit to enter the systemic circulation. The most common associated lesions are VSD, which occurs in almost half of the cases, pulmonary outflow tract obstruction, and, less commonly, coarctation of the aorta $(\approx 5 \%)$.D-TGA is one of the most common cyanotic defects seen in newborns, and when the ventricular septum is intact, it is usually cyanotic in the first day of life

C-TGA is a rare anomaly and comprises $<1 \%$ of all forms of congenital heart disease. In adults, it represents a very heterogeneous patient population, some of whom may not have been identified until adulthood. In this anomaly, the right atrium enters the morphological LV, which gives rise to the pulmonary artery, and the left atrium communicates with the morphological RV, which gives rise to the aorta. Thus, AV and ventriculoarterial discordance exists, and although blood flows in the normal direction, it passes through the "wrong" ventricular chamber. These patient may reach adulthood without any symptoms commonly.

The first credit of surgical treatment of TGA goes to Alfred Blalock and his then resident, Rollins Hanlon from Johns Hopkins. In 1948, in a joint paper, they described the essence of successful surgical "treatment" of TGA, allowing effective mixing of both the parallel circulations. Analyzing 123 cases of TGA from different sources, they concluded that the presence of a ventricular septal defect was favorable for survival, followed by the presence of an atrial septal defect. A combination of the two defects was the most favorable situation [4]. Armed with this information they realized that, surgical creation of a mixing site would improve the longevity of these patients. As the heart lung machine was yet to be brought into clinical use, a closed heart procedure was the only possible answer. In 1950, they first reported 
the use of a surgically created atrial septal defect as a treatment of TGA called the 'Blalock-Hanlon Septectomy' [5]. In spite of being a palliative procedure, this surgery laid the foundation of the surgical treatment of TGA and has been aptly described as an 'act of surgical genius' [6]. With the advent of 'balloon atrial septostomy (BAS), the Blalock-Hanlon septectomy eventually became redundant.

A historical review of surgical treatment of TGA will not be complete without acknowledging the role of BAS described for the first time by Rashkind and Miller from Philadelphia in 1966. The biggest advantage of BAS was, that an operation was not required and therefore, it allowed an effective palliation with relatively low risk in a precarious group of patients [7].

In 1957, Ake Senning, who had trained under Dr. Clarence Crafoord, performed the first successful atrial switch (Figure 2) using atrial flaps at the Karolinska Hospital, Stockholm, Sweden .It was published in 1959, as a sole author. The same article also describes unsuccessful attempts at an arterial switch. The procedure was unsuccessful in the first two patients. The third case, a 9-yearold boy survived. A cardiac catheterization done 6 weeks following this procedure showed excellent results. When asked to comment on use of an artificial material for atrial baffle, William T Mustard replied jokingly: "Use pericardium! The only excuse for using Dacron is if you drop the pericardium on the floor". On May 16, 1963, at the Hospital for Sick Children, Toronto, Mustard operated (Figure 3) upon an 18-month-old girl who had previously undergone a BlalockHanlon operation. He repaired the ventricular septal defect and then performed an atrial switch using an autologous pericardial baffle. The surgery was conceptually based on the Albert principle which Dr. Mustard duly acknowledged. The patient recovered uneventfully and was healthy till last reported in 2001. In this article, Mustard stated: "In my manuscript I gave credit to Dr. Albert for his original principles; the only problem with these procedures was that they did not work" [8]. By 1975, the Mustard procedure revealed its shortcomings including baffle obstruction and lack of growth potential [9]. This led to a resurgence of the Senning procedure where atrial wall was used rather than pericardium and it remained a favorite for the next decade.

Adib Dominos Jatene (Figure 4), a Brazilian surgeon of Lebanese origin performed successfully for the first time, a truly anatomical correction in the form of an ASO in 1975 at the University of Sao Paulo Heart Institute, Sao Paulo, Brazil. The first two patients were operated using profound hypothermia and total circulatory arrest. Coronary buttons were excised and the openings created were closed using homologous dura mater. After completing coronary transfer to the new site, the great vessels were transected; the ventricular septal defect was closed with a Dacron patch through a right ventriculotomy. The first patient, an 11-day-old female was extubated $6 \mathrm{~h}$ after surgery, but expired on the $3^{\text {rd }}$ postoperative day of renal failure. Necropsy showed a good anatomic correction. The second patient was a 40-day-old male who was successfully discharged 3 weeks after surgery. Jatene et al., stressed upon two technically important points excising coronary buttons and transecting the great vessels away from the valves. Unfortunately the next five patients expired within a few hours after surgery. The findings were presented at the $56^{\text {th }}$ Annual
Meeting of the American Association of Thoracic Surgery at Los Angeles in April 1976 and its significance as a surgical milestone was immediately recognized [10].

It was soon realized that a technically perfect coronary artery transfer was the most critical step in a successful ASO. As Jatene quotes "to divide, contrapose and then re-anastomose the great arteries is not a surgical problem. The major technical difficulty in this approach has been the transfer of coronary arteries" [10]. Hence, a detailed understanding of the possible variations in the origin and course of coronaries and its surgical management was an essential step towards it.

Yacoub and Radley-Smith from Harefield Hospital, United Kingdom divided the possible coronary anatomy into five types (A-E) based on the origin, course, and branching pattern. They also

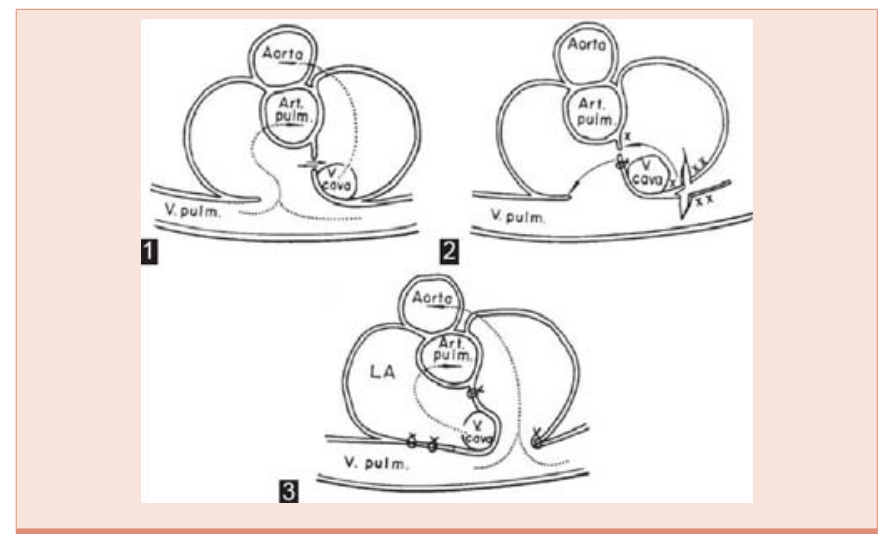

Figure 2: Senning operation. Preoperative (1), surgery (2), and b c postoperative (3); $X$ and $X X$ represent edges to be sutured. Arrows represent direction of blood flow. Art. pulm. = Pulmonary artery, $\mathrm{LA}=$ Left atrium, $\mathrm{V}$. cava $=$ Vena cava, $\mathrm{V}$. pulm. = Pulmonary vein (Reproduced with permission from: Senning A, Surgery; 1959; 45: 966-980.)

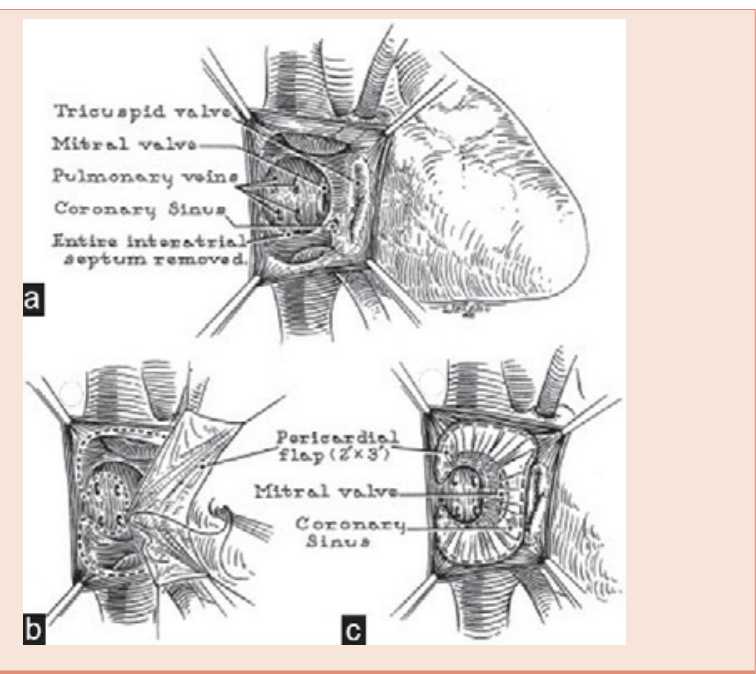

Figure 3: Mustard operation. Pericardial baffles are used to direct vena caval blood to mitral valve and pulmonary venous blood to tricuspid valve. (a) Atrial anatomy. (b) Suturing of pericardial baffle. (c) Completed procedure (Reproduced with permission from: Mustard WT, Surgery; 1964; 55: 469472.) 

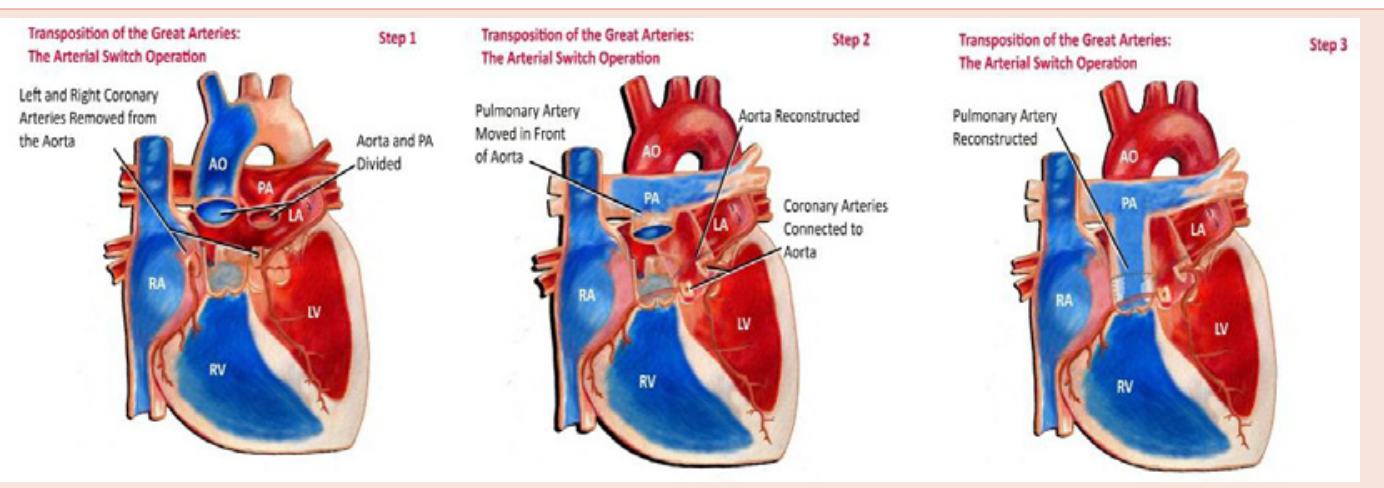

Figure 4: Jatene operation [The Arterial Switch Operation] (Reproduced with permission from: www.kidshearthouston.com).

described the method of surgical transfer of each type in 1978, thus providing newer insights and popularizing the operation further [11].

The most widely accepted system of classifying coronary anatomy in TGA is called the Leiden convention. It was initially proposed by Gittenberger-DeGroot et al., working with Quaegebeur's group based in Leiden, Netherlands [12]. In this system, the aortic sinuses are numbered based on the perspective of an imaginary person looking from the aorta to the PA. This has further simplified the understanding and conduct of the ASO.

In 1981, Lecompte from Laennec Hospital, Paris, France described a technically important modification of surgically translocating the great vessels, thereby avoiding the use of prosthetic conduit. This is now popularly called the 'Lecompte maneuver'. This greatly simplified the method of right ventricular outflow tract reconstruction during the ASO, besides providing a better anatomical lie for the coronary arteries and the newly reconstructed aortic anastomosis. This was a near revolution and nearly all surgeons round the world routinely perform this maneuver during the ASO [13].

It was soon realized that the arterial switch did not give acceptable results after the $1^{\text {st }}$ month of life. The inability of the LV to operate at a systemic pressure after regression of neonatal pulmonary hypertension was identified as the problem. Sir Magdi Yacoub from Harefield Hospital, United Kingdom proposed a two-stage repair by performing PA banding first, to train the LV followed by a second stage arterial switch several months or a year later. Thus, arose the concept of 'left ventricular training' [14].

The concept of rapid two-stage arterial switch for patients with TGA with intact septum presenting beyond neonatal period was introduced by Jonas and colleagues in 1989 [15]. The concept was based on studies on molecular biology of cardiac hypertrophy of the then Chief of Cardiology of Boston Childrens' Hospital; Dr Bernardo Nadal-Ginard. His work demonstrated that, in response to pressure load, there was a shift in the isoforms of heavy chain myosin and the changes were maximum at $48 \mathrm{~h}$ from the onset of pressure load [16]. In a rapid two-stage procedure, the first stage consists of pulmonary banding to provide the after-load with a modified BTS to provide a preload and improve the systemic oxygen saturation. This is followed by a corrective second stage arterial switch 5-7 days later.
The availability of mechanical circulatory support further allowed pushing the age limits of performing the arterial switch. [17] It was subsequently proved that the LV maintains its ability to support the systemic circulation well beyond the neonatal period. However, the time taken for the LV to undergo 'reconditioning' is a function of the age of surgery. If this period of temporary LV dysfunction is taken care of, using mechanical support like extracorporeal membrane oxygenation (ECMO), the age limit can be pushed to as much as 6 months. In addition, the ECMO supported approach also offers advantages of having to perform a single surgery, normoxemia, and progressive improvement in LV performance independent of the after-load and faster reconditioning period over the PA band-BTSbased two-stage approach [18].

As long-term results of arterial switch are being reported, newer sets of potential surgical problems are becoming evident. Progressive neo-aortic dilation (pulmonary valve at birth) has been observed. However, this dilation does not necessarily translate into aortic regurgitation (AR) and need for surgery in all patients.

Right ventricular outflow tract obstruction (RVOTO) was recognized as a complication within the first decade of the ASO being performed. It is one of the commonest causes of reintervention after ASO. The causes recognized include inadequate growth at the neo-pulmonary anastomotic site and inadequate mobilization of branch pulmonary arteries during the Lecompte maneuver. Apart from the Fontan palliation, very few surgical treatments have undergone such rapid evolution through various stages as that of TGA. History stands witness to a combination of brilliant innovation, technical ingenuity, and surgical expertise of multiple surgeons to whom this article is dedicated to. This overview shows that surgical techniques need continuous reappraisal and refinement. The quest to perform a perfect arterial switch remains a perpetual effort. The journey may have only just begun.

\section{References}

1. Baillie M (1797) The morbid anatomy of some of the most important parts of the human body. 2 nd ed. London: Johnson and Nicol 38.

2. Farre JR (1814) Pathological researches. Essay 1: On malformations of the human heart. London: Longman, Hurst, Rees, Orme and Brown 28.

3. Van Praagh R, Perez-Trevino C, Lõpez-Cuellar M, Baker FW, Zuberbuhler JR, et al. (1971) Transposition of the great arteries with posterior aorta, anterior pulmonary artery, subpulmonary conus and fibrous continuity between aortic and atrioventricular valves. Am J Cardiol 28: 621-631. 
4. Hanlon CR, Blalock A (1948) complete transposition of the aorta and the pulmonary artery: Experimental observations on venous shunts as corrective procedures. Ann Surg 127: 385-397.

5. Blalock A, Hanlon CR (1950) The surgical treatment of complete transposition of the aorta and the pulmonary artery. Surg Gynecol Obstet90: 1-15.

6. Weldon CS (1987) The Blalock-Hanlon operation. Ann Thorac Surg 43: 448 449

7. Rashkind WJ, Miller WW (1966) Creation of an atrial septal defect without thoracotomy. A palliative approach to complete transposition of the great arteries. JAMA 196: 991-992.

8. Mustard WT, Keith JD, Trusler GA, Fowler R, Kidd L (1964) The surgica management of transposition of the great vessels. J Thorac Cadiovasc Surg 48: 953-958.

9. Quaegebeur JM, Rohmer J, Brom AG (1977) Revival of the Senning operation in the treatment of transposition of the great arteries. Preliminary report on recent experience. Thorax 32: 517-524.

10. Jatene AD, Fontes VF, Paulista PP, Souza LC, Neger F, et al. (1976) Anatomic correction of transposition of the great vessels. J Thorac Cardiovasc Surg 72 : 364-370

11. Yacoub MH, Radley-Smith $\mathrm{R}$ (1978) Anatomy of the coronary arteries in transposition of the great arteries and methods for their transfer in anatomical correction. Thorax 33: 418-424.
12. Gittenberger-de Groot AC, Sauer U, Oppenheimer-Dekker A, Quaegebeur J (1983) Coronary arterial anatomy in transposition of the great arteries: A morphologic study. Pediatr Cardiol 4: 15.

13. Lecompte Y, Zannini L, Hazan E, Jarreau MM, Bex JP, et al. (1981) Anatomic correction of transposition of the great arteries. J Thorac Cardiovasc Surg 82: 629-631.

14. Yacoub MH, Radley-Smith R, Maclaurin R (1977) Two-stage operation for anatomical correction of transposition of the great arteries with intact interventricular septum. Lancet 1: 1275-1278.

15. Jonas RA, Giglia TM, Sanders SP, Wernovsky G, Nadal-Ginard B, et al (1989) Rapid, two-stage arterial switch for transposition of the great arteries and intact ventricular septum beyond the neonatal period. Circulation 80 : 1203-1208.

16. Izumo S, Nadal-Ginard B, Mahdavi V (1988) Protooncogene induction and reprogramming of cardiac gene expression produced by pressure overload. Proc Natl Acad Sci U S A 85: 339-343.

17. Mee RB, Harada Y (1991) Retraining of the left ventricle with a left ventricular assist device (Bio-Medicus) after the arterial switch operation. J Thorac Cardiovasc Surg 101: 171-173.

18. Kang N, de Leval MR, Elliott M, Tsang V, Kocyildirim E, et al. (2004) Extending the boundaries of the primary arterial switch operation in patients with transposition of the great arteries and intact ventricular septum. Circulation 110: II123-127.

Copyright: (c) 2016 Nagre SW. This is an open-access article distributed under the terms of the Creative Commons Attribution License, which permits unrestricted use, distribution, and reproduction in any medium, provided the original author and source are credited. 